\title{
Facial Spasm and Paroxysmal Tinnitus Associated with an Arachnoid Cyst of the Cerebellopontine Angle
}

\author{
-Case Report-
}

\author{
Shingo TAKano, Tooru MARuno*, Shizuo ShIRAI*, and Tadao NOSE
}

Department of Neurological Surgery, Institute of Clinical Medicine, University of Tsukuba, Tsukuba, Ibaraki; *Department of Neurosurgery, Soujinkai Hospital, Ibaraki

\begin{abstract}
A 59-year-old female presented with a 3-year history of hemifacial spasm and paroxysmal tinnitus associated with an arachnoid cyst of the cerebellopontine angle, which was identified preoperatively by magnetic resonance imaging. Surgical decompression of the cyst and arterial decompression of the facial and acoustic nerves at their root exit zones resulted in complete resolution of the symptoms.
\end{abstract}

Key words: cerebellopontine angle, arachnoid cyst, hemifacial spasm, tinnitus

\section{Introduction}

Hemifacial spasm, sometimes associated with hyperdysfunction of the acoustic nerve such as tinnitus, is most commonly caused by compression of the facial and acoustic nerve roots by an aberrant vessel, usually a branch of the anterior inferior cerebellar artery (AICA), posterior inferior cerebellar artery, or vertebral artery. ${ }^{9)}$ More serious but rarer causes of compression include posterior circulation aneurysms, ${ }^{12)}$ vascular malformations, ${ }^{1,16]}$ and various types of tumors. ${ }^{2,8,11,13 !}$ We report a rare case of a cerebellopontine (CP) angle arachnoid cyst that indirectly caused hemifacial spasm and tinnitus.

\section{Case Report}

A 59-year-old female was admitted to our hospital on April 1995, with a chief complaint of twitching of the left facial muscles and paгохysmal tinnitus on the left side for 3 years. The spasm originated in the orbicularis oculi and extended to the lower part of the face. She had been treated with tranquilizers for several months without obvious beneficial effects before referral. The spasm and paroxysmal tinnitus had become more severe and more frequent. No other neurological abnormalities including hearing deficits were detected.

Received May 19, 1997; Accepted November 21, 1997
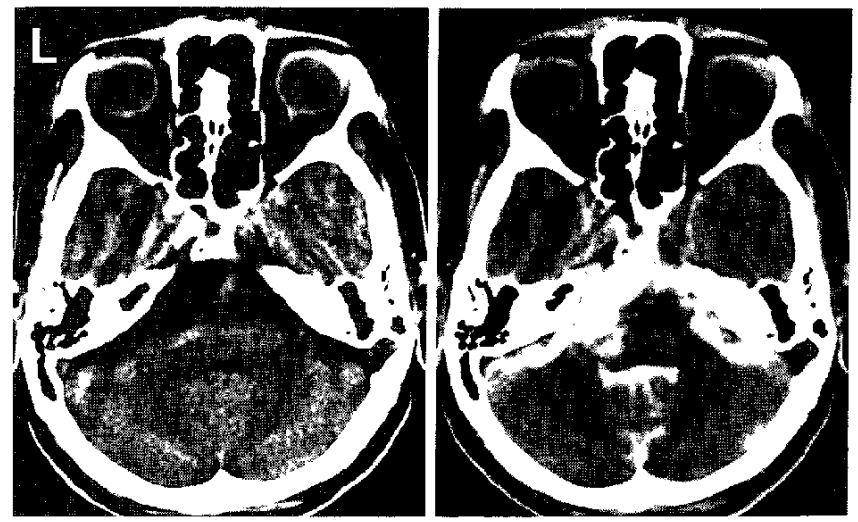

Fig. 1 Computed tomography (CT) scan showing a cystic lesion in the left cerebellopontine angle and brain stem displacement (left). Metrizamide CT cisternogram showing a cystic lesion well filled with contrast medium 3 hours after injection (right).

Computed tomography [CT] demonstrated a homogeneous lesion in the left CP angle with similar density to the cerebrospinal fluid (Fig. 1 left). Metrizamide CT cisternography revealed no filling defect in the left CP angle 3 hours after injection (Fig. 1 right) and similar clearance 48 hours after injection. Magnetic resonance (MR) imaging showed enlargement of the left CP angle cistern, which had caused deviation of the lower pons (Fig. 2 left). Coronal MR imaging demonstrated the vascular 


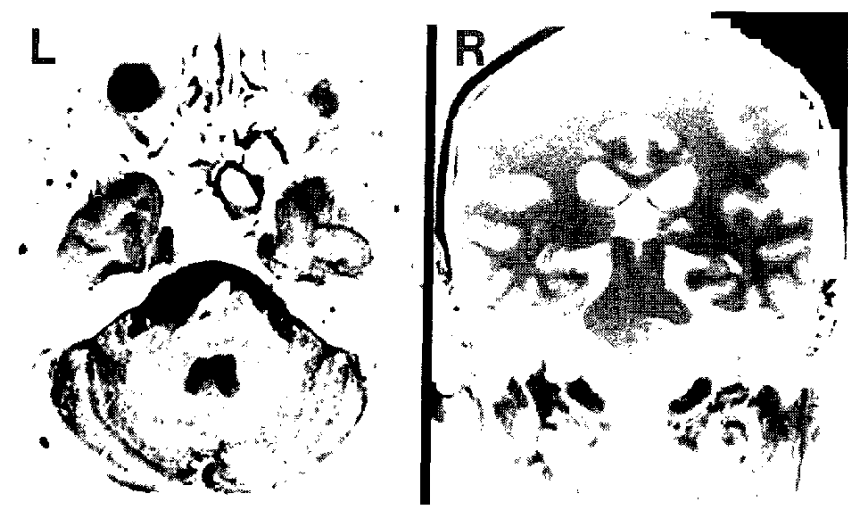

Fig. 2 Axial $\mathrm{T}_{2}$-weighted magnetic resonance (MR) image showing enlargement of the left cerebellopontine angle cistern and brain stem deviation (left). Coronal $\mathrm{T}_{1}$-weighted MR image showing the vascular loop impinging on the pontomedullary junction (right).

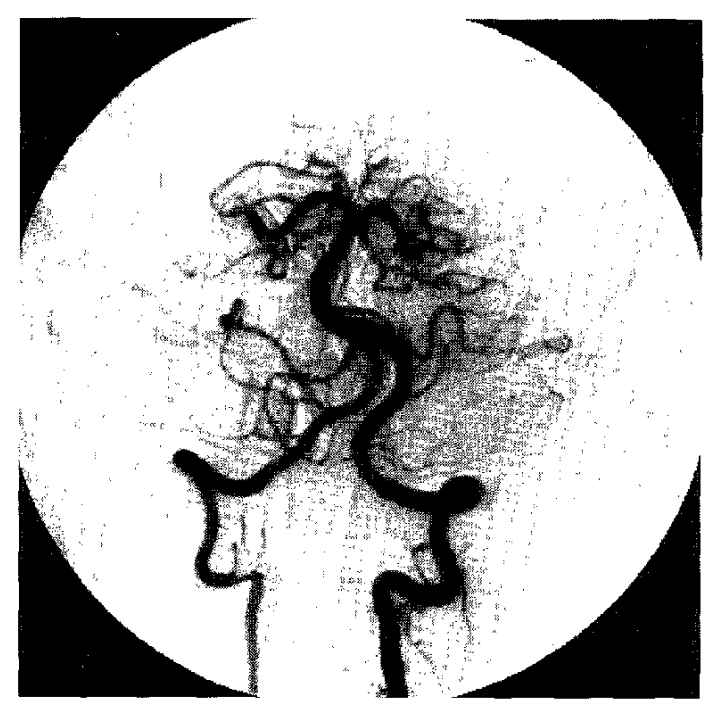

Fig. 3 Left vertebral angiogram showing elongation of the left vertebral artery and anterior inferior cerebellar artery.

loop impinging on the left pontomedullary junction [Fig. 2 right). Vertebral angiography disclosed elongation of the left vertebral artery and the left AICA (Fig. 3).

The diagnosis was vascular cross-compression of the facial and acoustic nerves associated with a left CP angle arachnoid cyst. Microvascular decompression and cyst decompression by the suboccipital approach were performed in May 1995. Exposure of the cyst in the CP angle showed the cyst wall was clear and transparent. The cyst was located around

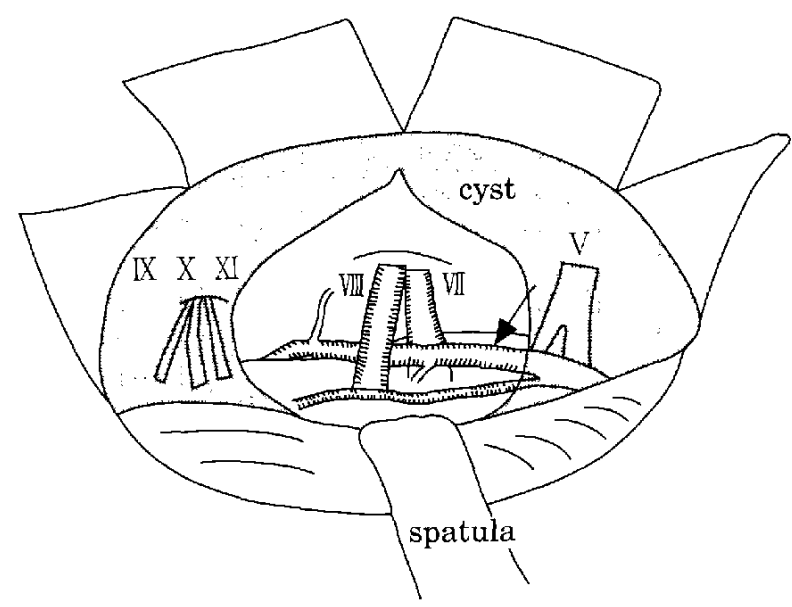

Fig. 4 Schematic drawing of the intraoperative exposure, showing the arachnoid cyst (the outer wall opened) with stretched facial (VII) and acoustic (VIII) nerves and the large branch of anterior inferior cerebellar artery (arrow) running between the VII and the VIII nerves compressing the VII nerve ventrally and the VIII nerve dorsally.

the facial and acoustic nerves and extended from the porus acousticus to the brain stem. Excision of the outer wall of the cyst allowed clear cerebrospinal fluid to escape from the cyst. Histological examination of the cyst wall biopsy specimen indicated reactive arachnoid membrane. Two branches of the AICA were located around the facial and acoustic nerves. One large branch ran between the facial and acoustic nerves and another small branch ran along the dorsal aspect of acoustic nerve, compressing the facial nerve ventrally and pinching the acoustic nerve at the root exit zone (Fig. 4). The large branch of the AICA was separated from the facial and acoustic nerves and small pieces of Teflon felt were inserted between the artery and the facial nerve, and between the artery and the acoustic nerve. The small branch of the AICA was separated from the acoustic nerve by careful dissection of the arachnoid between the artery and the nerve so that neither artery could compress the facial and acoustic nerves directly. The Teflon felts were fixed to the dura of the petrous bone side to prevent displacement.

Immediate postoperative condition was excellent, and she was completely relieved of hemifacial spasm and tinnitus. At follow-up 2 years after the operation, she continued to be free of the symptoms and MR imaging demonstrated the size of the arachnoid cyst was reduced (Fig. 5). 


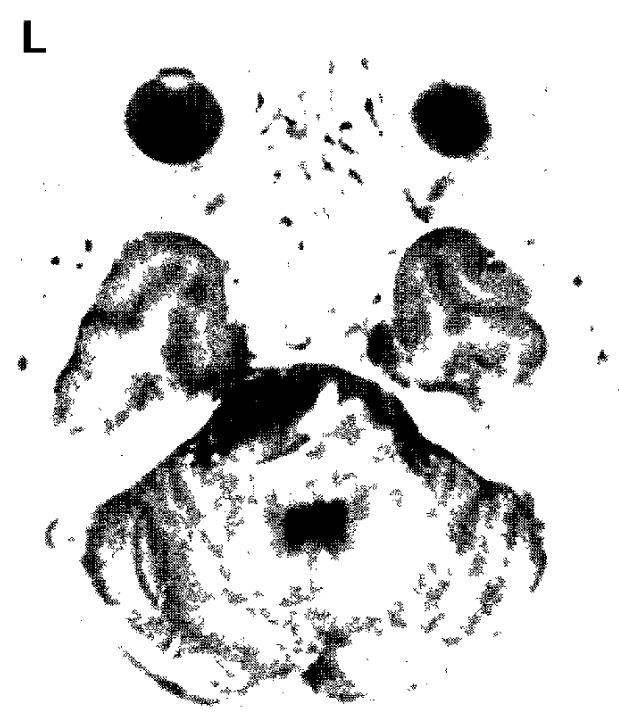

Fig. 5 Postoperative $T_{2}$-weighted magnetic resonance image showing reduced size of the cyst.

\section{Discussion}

The clinical symptoms produced by a cyst in the CP angle may closely mimic those of an acoustic neurinoma, with sensorineural hearing loss, impaired corneal reflex, trigeminal neuralgia, and in the late stages cerebellar signs and increased intracranial pressure. $^{3,17)}$ In our patient, the GP angle arachnoid cyst had caused compression of the brain stem, resulting in stretching or bending of the facial and acoustic nerves ${ }^{14]}$ and deviation of the ipsilateral AICA., ${ }^{4,5,18)}$ The secondary result was contact between the AICA and the root exit zone of the facial and acoustic nerves. Hyperactive dysfunction of the acoustic nerve, such as tinnitus, associated with facial spasm may be caused by cross-vascular compression of the facial and acoustic nerves at their root exit zone. ${ }^{7,9,10,15)}$ A similar case of hemifacial spasm associated with CP angle arachnoid cyst was previously described. ${ }^{6)}$ Evacuation of the arachnoid cyst alone had no beneficial effect, and the additional microvascular decompression was needed for the relief of hemifacial spasm. Another case of hemifacial spasm associated with cerebellar arachnoid cyst was treated effectively by removal of the cyst and decompression of the facial nerve. ${ }^{1)}$ Like other CP angle tumors responsible for hemifacial spasm or other cranial nerve compression syndromes, ${ }^{\text {9) }}$ the CP angle arachnoid cyst may be only indirectly responsible for the syndrome, acting by displacing a small artery to impinge upon the root entry zone of the affected facial and acoustic nerves. Successful treatment of hemifacial spasm associated with CP angle arachnoid cyst can be achieved by decompression of the cyst and arterial decompression at the nerve root exit zone.

\section{References}

1) Altinörs N, Karz Z, Çepoglu C: Rare causes of hemifacial spasm. Report of two cases. Clin Neurol Neurosurg 93: 155-158, 1991

2) Auger RG, Pipgras DG: Hemifacial spasm associated with epidermoid tumors of the cerebellopontine angle. Neurology 39: 577-580, 1989

3) Babu R, Murali R: Arachnoid cyst of the cerebellopontine angle manifesting as contralateral trigeminal neuralgia: case report. Neurosurgery 28: 886-887, 1991

4) Cook BR, Janetta PJ: Tic convulsif: results in 11 cases treated with microvascular decompression of the fifth and seventh cranial nerves. J Neurosurg 61: 949951, 1984

5) Haddad FS, Taha JM: An unusual cause for trigeminal neuralgia: contralateral meningioma of the posterior fossa. Neurosurgery 26: 1033-1038, 1990

6) Higashi S, Yamashita J, Yamamoto $Y$, Izumi K: Hemifacial spasm associated with a cerebellopontine angle arachnoid cyst in a young adult. Surg Neurol 37: 289-292, 1992

7) Isu T, Ito T, Murai $H$, Yamamoto K: Paroxysmal tinnitus and nystagmus accompanied by facial spasm. Surg Neurol 23: 183-186, 1985

8) Iwasaki K, Kondo A, Otsuka S, Hasegawa K, Ohbayashi T: Painful tic convulsif caused by a brain tumor: case report and review of the literature. Neurosurgery 30: 916-919, 1992

9) Janetta PJ: Cranial nerve and brain neurovascular compression syndromes, in Horowitz $\mathrm{O}$, McCombs PR, Roberts B (eds): Diseases of Blood Vessels. Philadelphia, Lea \& Febiger, 1985, pp 85-96

10) Kondo A, Ishikawa I, Hiwatashi $S$, Yamasaki $T$, Koyama $\mathrm{T}$ : [Surgical results of the treatment of hemifacial spasm, tinnitus and trigeminal neuralgia by the method of "microvascular decompression"]. No Shinkei Geka 7: 677-685, 1979 (Jpn, with Eng abstract)

11) Levin JM, Lee JE: Hemifacial spasm due to cerebellopontine angle lipoma: case report. Neurology 37: $337-339,1987$

12) Maroon JC, Lunsford LD, Deeb ZL: Hemifacial spasm due to aneurysmal compression of the facial nerve. Arch Neurol 35: 545-546, 1978

13) Miyazaki $S$, Fukushima $T$, Nagai A, Tamagawa $T$ : [CP angle meningioma presenting as hemifacial spasm]. No Shinkei Geka 15: 683-686, 1987 (Jpn, with Eng abstract)

14) O'Coneell JEA: Trigeminal false localizing signs and their causation. Brain 101: 119-142, 1978 
15) Ohashi N, Yasumura S, Nakagawa H, Mizukoshi K, Kuze S: Vascular cross-compression of the facial and acoustic cranial nerves. J Laryngol Otol 106: 436-439, 1992

16) Pierry A, Cameron M: Chronic hemifacial spasm from posterior fossa arteriovenous malformation. $J$ Neurol Neurosurg Psychiatry 42: 670-672, 1979

17) Rengachary SS: Intracranial arachnoid and ependymal cysts, in Wilkins RH, Rengachary SS (eds): Neurosurgery. New York, McGraw-Hill, 1985, pp 21602172
18) Snow RB, Fraser RAR: Cerebellopontine angle tumor causing contralateral trigeminal neuralgia. Neurosurgery 21: 84-86, 1987

Address reprint requests to: S. Takano, M.D., Department of Neurological Surgery, Institute of Clinical Medicine, University of Tsukuba, 1-1-1 Tennoudai, Tsukuba, Ibaraki 305-8575, Japan. 